\title{
Caio Prado Júnior e Os sertões, de Euclides da Cunha
}

Giovana Beraldi Faviano ${ }^{1}$, Talita Yosioka Collacioํㅜ, Viviane Vitor Longo $^{1}$, Prof. Dr. Alexandre de Freitas Barbosa ${ }^{2}$, Elisabete Marin Ribas $^{3}$

Em 1960, é publicada uma reportagem no jornal Correio do Povo de Porto Alegre, em que Caio Prado Jr. declara que as descrições sobre o Nordeste, presentes em Os sertões, de Euclides da Cunha, de 1902, são "inteiramente falsas. Não existem”. Diante de tal declaração, a Casa Euclidiana escreve ao intelectual, solicitando uma apreciação sobre o livro. Em sua resposta, Caio Prado Jr. elabora sua crítica, explicando os motivos pelos quais considera que a saga euclidiana tem mais importância como expressão literária do que como análise da realidade.

Em suma, Caio Prado Jr. aponta que, apesar das diferenças entre os "sertões reais" e os sertões registrados no livro, o valor da obra de Euclides da Cunha se deve, sobretudo, à denúncia das mazelas sociais, que ocorrem nessa região do Brasil e atravessam o século XX. Vale notar que, depois de contrapor o sertão historiográfico ao sertão literário, Caio Prado não deixa de tecer loas ao seu mestre: "o pensamento brasileiro, com Euclides da Cunha, começa a adquirir maioridade". Enfim, um diálogo de gigantes que a Revista do IEB presenteia aos leitores interessados nas "coisas do Brasil".

A seguir, reproduzimos a carta na íntegra, com a ressalva de que os erros datilográficos foram corrigidos e atualizada a ortografia.

1 Estagiárias do Fundo Caio Prado Jr.

2 Docente da área de História, IEB-USP.

3 Supervisora técnica do Serviço de Arquivo, IEB-USP.

revista ieb $n_{54} 2012$ set./mar. p. I89-194 
São Paulo, 26 de abril de 1960.

Ilmo. Sr.

Prof. Arivelsio Padilha

Casa Euclidiana

São José do Rio Pardo

Em ofício de 29 de março, que recebi com grande atraso, Vossa Senhoria estranha afirmação que eu teria feito em entrevista concedida a jornal de Porto Alegre, a respeito de Euclides da Cunha. O texto da entrevista, de que só tive conhecimento depois de publicado, não reproduz fielmente o que afirmei em simples conversa a um jornalista, conversa essa transformada em entrevista. Referindo-me à discordância tão comum no passado, entre o tratamento dado à realidade brasileira em nossa literatura (e não só a de ficção), e essa realidade tal como de fato se apresenta, tive ocasião de afirmar que dessa visão deformadora não escaparam muitas vezes nem mesmo alguns dos maiores escritores brasileiros que procuravam precisamente ajustar seus conceitos e ideias aos fatos reais e concretos da vida brasileira. Citei então, a propósito, o nome de Euclides da Cunha, mas sem aquela ênfase e maneira peremptória que transparece no texto da entrevista.

Não me é possível desenvolver aqui às pressas (que as circunstâncias me impõem) o meu verdadeiro e completo pensamento a respeito do assunto, e os motivos da restrição que fiz, e faço, à grande obra de Euclides da Cunha. Não quero todavia fugir inteiramente ao repto, delicado embora, mas sempre - repto que se insinua em seu ofício.

Os Sertões de Euclides da Cunha não dão, em conjunto, a meu ver, uma ideia rigorosamente adequada dos sertões reais do Nordeste. Experimentei-o pessoalmente quando, por ocasião de meu primeiro contato com aquela região (já lá vão dessa data quase trinta anos), procurei muitas vezes, sem encontrar, a imagem que trazia dos Sertões euclidianos, e que o entusiasmo do leitor juvenil daquela época, pelo grande escritor, gravara em meu pensamento. Esse desaponto deu lugar mais tarde, depois de novas leituras dos Sertões, e de outras e repetidas viagens pelos sertões reais, à conclusão de que efetivamente o grande literato e primoroso estilista, que foi Euclides da Cunha, se imprimira muito mais nos Sertões, que o observador e analista social.

revista ieb $n_{54} 2012$ set./mar. p. I89-194 
Não encontrei nos sertões reais, por mais que o procurasse, e creio que ninguém neles encontre, o épico dos Sertões euclidianos, esta raça de centauros heroicos que constituiriam uma preciosa reserva de forças potenciais para a nacionalidade brasileira. Nada vi, nem penso que se possa ver nos sertões reais, o que se assemelhe à "integridade orgânica do mestiço que desponta inteiriça e robusta, imune de estranhas mesclas capaz de envolver diferenciando-se, acomodando-se a novos e mais altos destinos, porque é a sólida base física do desenvolvimento moral ulterior" (p. 112 da 9a edição, 1926).

O que os sertões reais apresentam (foi para mim, e ainda é, uma das mais dolorosas observações, que muito contribuiu para o rumo que tomou minha vida) é um mundo em decomposição, onde vegeta uma população cujo estado físico e moral se pode dizer degradante para a espécie humana.É a miséria mais sórdida, na extensão da palavra, e que rebaixa o homem para níveis que já se podem dizer abaixo dele.

Não é isso que nos dizem os Sertões... Mas - e é nisso, a meu ver que os Sertões euclidianos mais se apartam da realidade - essa gente sertaneja absolutamente não constitui, como pretendeu Euclides da Cunha, uma sociedade espacialmente apartada e segregada do resto do Brasil, formando, insulando no país um conjunto discriminado, distinto e internamente homogêneo. É assim que os Sertões euclidianos retratam os sertões reais. Nada mais falso. Nos sertões do Nordeste, como no resto do país, a diferenciação e discriminação não é territorial e horizontal, e sim vertical e social. Aquela gente - miserável, muitas vezes molambos humanos apenas, e que forma a grande massa da população, não constituiu toda essa população e sociedade sertaneja. Como em toda parte do mundo de hoje (o "nosso" mundo) há também a minoria dos bem-acomodados na vida, e que, bem pequena embora, se destaca desde logo, a começar pelo físico e a indumentária, seja nos centros urbanos, mesmo dos menores, seja nos aglomerados rurais. Compõem-na proprietários, seus administradores e gerentes, comerciantes, profissionais, funcionários públicos..., para os quais, direta ou indiretamente, se escoa o fruto do trabalho tão penoso da maioria miserável.

Os Sertões euclidianos não retratam nada disso, e é só muito breve e incidentemente que se referem às idílicas relações de classe entre vaqueiros e proprietários ausentes (p. 122 e 124). Tem-se assim, ao ler os Sertões, a falsa impressão de um mundo à parte e segregado onde formou e evoluiu uma sociedade sui generis, física e moralmente bem caracterizada e individualizada que se integra num conjunto orgânico e harmonioso, primitivo embora, mas estuante de potencialidades. 
Essa falsa imagem dos sertões reais, que os Sertões euclidianos fixaram no pensamento brasileiro, tem pesado consideravelmente, e negativamente, bem-entendido, nas nossas concepções políticas. Ainda que de maneira mais ou menos confusa e imprecisa, tem-se entendido, e se entende ainda muitas vezes, que o problema do sertão nordestino consiste em "integrar" essa região isolada e diferenciada no organismo da nação brasileira em que não se assimilou inteiramente. Isso tem levado a não poucas soluções falsas, de que se ressentem desde as Obras contra as Secas, até a recentíssima Operação Nordeste.

Mas não posso agora estender-me nesses pontos. É possível que as discordâncias que descubro entre os Sertões euclidianos e os sertões reais se devam em parte a uma perspectiva diferente no tempo (entre os sertões de Euclides e os nossos, medeiam muitos decênios), e perspectiva também diferente no espaço (Euclides conheceu apenas, que eu saiba, um pequeno setor do sertão setentrional da Bahia - mas falou dos sertões em geral). É isso talvez que o tenha levado a afirmar que “todo sertanejo é vaqueiro", e que a agricultura se reduz a rudimentares plantações da vazante, pela beira dos rios, para aquisição de meios de primeira necessidade (p. 122. Noto incidentalmente que essas plantacões de vazante a que se refere Euclides não são na beira dos rios, e sim no próprio leito, salvo apenas no S. Francisco, único rio perene do sertão). O que Euclides afirma na passagem citada é só meia verdade, pois em diferentes regiões tipicamente sertanejas, aliás as relativamente mais povoadas - como o Sertão Alto e o Sertão do Araripe, em Pernambuco, o Alto Sertão, na Paraíba, a Serra Geral na Bahia, a região Serrana no Rio Grande do Norte, e tantas outras -, a agricultura é muito mais importante que a pecuária, tem uma expressão econômica apreciável, e a ela se dedica a maior parte da população. O "vaqueiro" é aí quase uma exceção. Curioso como essa ideia de que os sertões nordestinos são exclusivamente pastoris se difundiu e fixou, a ponto de ser generalizadamente aceita e sempre repetida. Acredito que a força dessa ideia está na tradição legada pelos Sertões euclidianos...

Não julgue Vossa Senhoria que seja minha intenção diminuir a importância e valor dos Sertões, e muito menos de Euclides da Cunha, apontando as discrepâncias com a realidade que encontro na obra do grande escritor. Essas discrepâncias não importam, porque a grande contribuição de Euclides foi o desassombro e a coragem com' que, em meio à hipocrisia característica do seu tempo, ele denunciou as mazelas sociais do país. O impacto emocional que isso produziu teve o mais largo efeito, pois ensinou as novas gerações a olharem diferentemente para o Brasil e suas coisas. Elas já não procurarão mais, como fora em regra no 
passado, imitar a cultura europeia, escondendo envergonhadas tudo que nos distingue daquela cultura. O pensamento brasileiro, com Euclides da Cunha, começa a adquirir maioridade.

Lamento não ser mais extenso, mais preciso, mais ordenado no atendimento do..., seja lá o que for, de Vossa Senhoria. Queira aceitar minhas escusas e os atenciosos cumprimentos.

Caio Prado Júnior.

\section{Referência: \\ Arquivo do Instituto de Estudos Brasileiros USP - Fundo Caio Prado Jr., código do documento: CPJ-CP- CРJ-CA024a}

\section{Detalhes técnicos:}

Remetente: Caio Prado Júnior

Destinatário: Casa Euclidiana/Prof. Arivelsio Padilha

Número de folhas: 4

Data tópica: São Paulo

Data cronológica: 26 de abril de 1960

Suporte: Papel sulfite

Dimensões do documento: $31,5 \mathrm{~cm}$ x 21,5 cm

Técnica de registro: datilografado

\section{Informações sobre o "Fundo Caio Prado Jr." no IEB}

Desde que o Fundo Caio Prado Jr. foi adquirido pelo IEB, com recurso da Fapesp, em 2002, seu conjunto documental tem passado por procedimentos de identificação, acondicionamento e catalogação, com o intuito de disponibilizá-lo para pesquisa. Há um ano e meio, foi iniciada nova metodologia em seu processo de catalogação, visando a identificar, a partir da totalidade do fundo, cada item documental. Esse trabalho consiste na leitura e indexação individualizada de cada documento, devidamente inserido em um quadro de arranjo, por meio de critérios arquivísticos de tipologia documental e separação em grupos, dossiês e séries.

revista ieb $n_{54} 2012$ set./mar. p. I89-194 
Para tal organização, foi necessária uma triagem rápida que percorresse todo o acervo, com vistas a conhecer os tipos documentais e as possíveis séries e dossiês que comporiam sua disposição. Assim, o cadastro documental está sendo realizado pela equipe composta pelas estagiárias Giovana Beraldi Faviano, Talita Yosioka Collacio e Viviane Vitor Longo, sob a supervisão técnica de Elisabete Marin Ribas e a orientação acadêmica do Prof. Alexandre de Freitas Barbosa. Além disso, também são realizadas reuniões periódicas com especialistas na obra de Caio Prado Jr. e áreas afins, que auxiliam na reflexão em torno dos documentos e, por consequência, na lógica da sua organização.

Estima-se que o Fundo Caio Prado Jr. contenha aproximadamente 30 mil documentos, dos quais 7 mil se encontram devidamente catalogados e 4 mil já estão disponíveis para consulta, subdivididos nos seguintes itens: Correspondência Ativa, Cartões-Postais, Diários Políticos e os Dossiês AGB, Fazenda Guatapará e Maurício Goulart. 